\title{
Results of Surgical Treatment of Patients with Congenital Auditory Canal Atresia and Microtia
}

\author{
Kh. M. Diab, N. A. Daikhes, D. N. Nazaryan, \\ D. S. Kondratchikov; O. A. Pashchinina, O. S. Panina \\ Federal Research Clinical Center of Otorhinolaryngology of \\ Federal Medical Biological Agency of Russia, \\ (Director-Professor N. A. Daikhes), 123182, Moscow, Russia
}

\begin{abstract}
Purpose: Creation and implementation effective methods of complex anatomical, functional and aesthetic rehabilitation for different categories of patients with atresia of the external auditory canal (AEAC) and microtia.

Methods: Fourty seven patients $(n=47)$ with congenital atresia of external auditory canal and microtia of different grade underwent surgery on the base of ear diseases department of Federal Scientific and Clinical Center of Otorhinolaryngology (FSCCO) of Federal Medico-Biological Agency of Russian Federation. All patients were divided into three groups. The first group included patients with EACA and 1 grade microtia. The second group included patients with EACA and 2-3 grade microtia. The third group included patients with AECA and 2-3 grade microtia who underwent different types of surgeries previously, had unsufficient development of local tissue, history of trauma, radiation or auricular cancer. To all of them one of three surgical approaches was performed due to individual features and indications: formation of an EAC, tympanoplasty with ossicular chain reconstruction $(\mathrm{n}=23)$ to the $1^{\text {st }}$ group of patient; formation of an EAC, tympanolasty with ossicular chain reconstruction and concomitant reconstruction of an auricle by use of MEDPORto the $2^{\text {nd }}$ group of patients $(n=9)$ or fixation of cranial osseointegrated implants (COI) to the $3^{\text {rd }}$ group of patients $(n=15)$.

Results: During the observation period which covered on average 3.2 years $(+.9$ months) achieved stable anatomical result. The air-bone gap was on the average $17,0 \pm 3.2 \mathrm{~dB}$. Medpor reconstruction provided reliable aesthetic results. The removable auricural prosthesis completely covered up a congenital defect and was a reflection of a healthy ear.

Conclusion: The application of the method of lining the formed bone walls of the external auditory canal with a skin pedicled flap and free skin grafts makes it possible to achieve stable anatomical result. Ossiculoplasty with titanium prostheses and tympanoplasty with auto-fascia graft provide a significant hearing improvement in patients with congenital atresia of the external auditory canal. Simultaneous surgical interventions with atresia repair; tympanoplasty and Medpor implantation or setting of ectoprosthetic on COI can be successfully used to improve hearing, replace abnormal ear in different categories of patients according to indications and return them to the social life.
\end{abstract}

Key words (5): congenital aural atresia, microtia, tympanoplasty, anaplastology, medpor

\section{Introduction}

Among the various congenital anomalies of the ear the most common is a combined defect, known as atresia of the external auditory canal (AEAC). It includes anomalies in the development of the external auditory canal, the middle ear and concomitant defect of the auricle [1].

The incidence of AEAC is 1 case in 10,000-20,000 live births [2]. Unilateral defects in the development of external and middle ear are more common than bilateral cases (mainly affected the right side 58-61\%) [3]. Patients with this pathology suffer not only from severe conductive hearing loss, but also from a gross cosmetic defect.

Reconstructive surgeries aimed at the formation of the auricle and external auditory canal and repair of the middle ear structures for restoration of acoustic function. These surgeries are technically complex and far from the expected aesthetic and functional outcomes, especially in case of Goldenhar syndrome (hemifacial microsomia) when the auricle is much lower in space $[4,5]$. In addition, they are associated with a high risk of postoperative complications. The most common are restenosis of the external auditory canal and the lateralization of the tympanic graft dislocation, which require repeated surgical interventions in 30-46\% [6]. Bone obliteration of the auditory canal causes additional difficulties during surgery. Its removal using cutters often leads to the development of sensoneural 
hearing loss (SHL) due to excessive vibration on the receptor cells of the inner ear transmitted from the atretic plate through the chain of auditory ossicles [7]. Cases of congenital AEAC are also often accompanied by an atypical location of the facial nerve: the tympanic segment is usually displaced down and the mastoid segment of the nerve is located more anterior, what increases the risk of it's damage $[8,9]$.
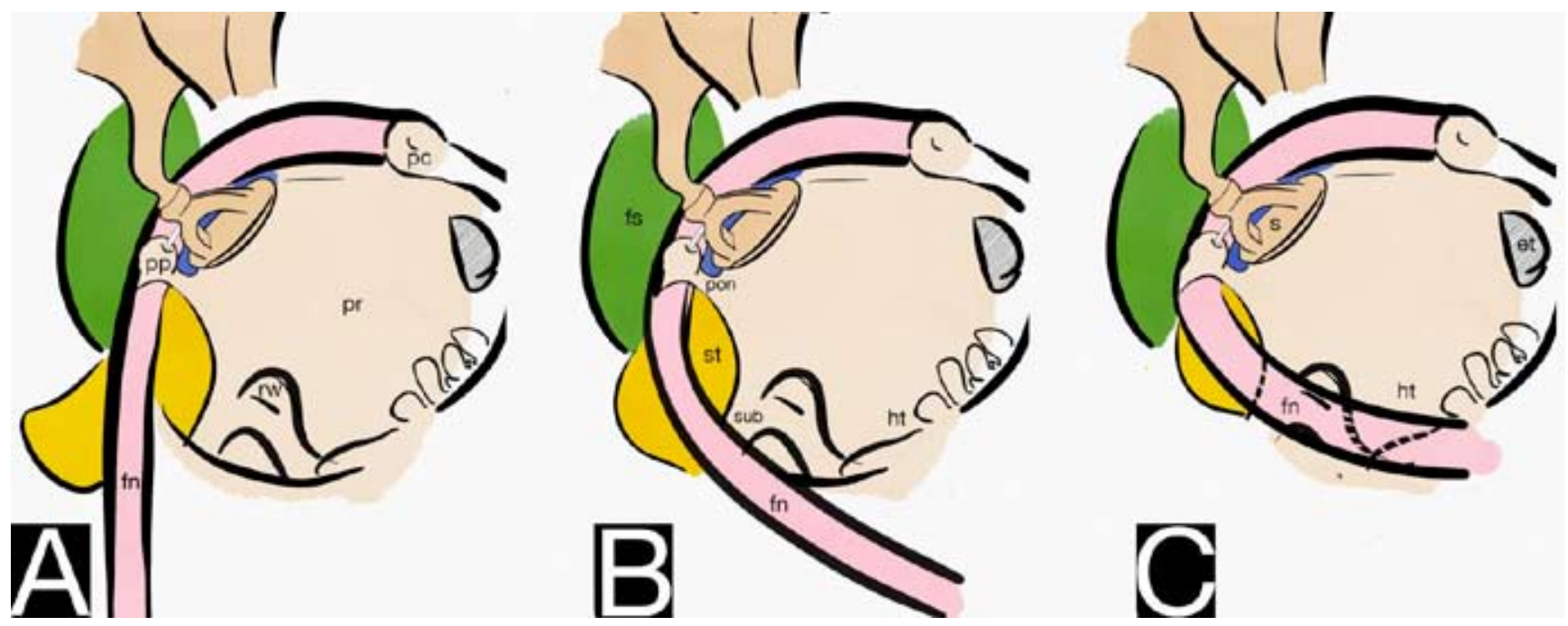

Legend: $f n$ - facial nerve; pp - processus pyramidalis; pc - processus cochleariformis; pr - promontorium; rw - round window; pon - ponticulus; sub - subiculum; st - sinus tympani; fs - facial sinus; ht - hypotimpanum; s - stapes; et - Eustachian tube

Figure 1. Facial nerve position.

Several modalities are available for auricular reconstruction in case of microtia: autologous costal cartilage, silastic frameworks, porous polyethylene implants and prosthetic implants. One of the initial management decisions a surgeon needs to make is to determine whether to use autologous, alloplastic, or prosthetic material for the ear construct depending on the severity of microtia and functional goals following surgical correction.

In addition, type III microtia by $\mathrm{H}$. Weerda classification (when the patient has no recognizable auricular structures) requires large additional skin or cartilage fragments for complex reconstruction [10].

Porous polyethylene implantation beneath a TPF flap and full-thickness skin graft is completed in less procedures and shorter operative times than autologous costal cartilage repair. Because of a possibly simplier operative and postoperative process, Medpor implantation is used as the standard approach to total auricular reconstruction by many plastic surgeons [11]. In most cases reconstruction with use of Medpor/Supor held for children or young patients without history of surgeries.However, there are certain disadvantages associated with using alloplastic reconstruction of the auricle. Such as, extraction or exposition of the implant due to flap necrosis or skin graft failure,also the framework can be displaced or fractured. In addition, the need for a TPF flap for adequate soft tissue coverage over the implant sacrifices a salvage procedure for complicated framework infections. Insufficient development of local tissues for autogenous reconstruction, unsatisfactory outcomes of previous interventions, previous history of auricular cancer resection, radiation, or trauma lead to scarred, poorly perfuse mastoid skin that would alter viability of a local flap. A contralateral TPF flap can still be utilized for salvage procedures, but Medpor reconstruction cannot be repeated once flaps from both sides have been already used. In such cases ectoprostetics on cranial osseointegrated implants (COI) may be the best choise and sometimes the only possible way of aesthetic rehabilitation [12].

Nowadays most researchers agree that in some cases the repair of the ear, eye, nose, orbit, zygomatico-orbital complex by ectoprosthetics on cranial osseointegrated implants results in an aes- 
thetically more satisfactory otcomes than the use of autologous reconstruction.In the otologic surgery the COI widely used in hearing aids by bone sound engineering devices [13].The frequency of skin reactions in most cases does not exceed second degree according to Holgers grading system. The functional viability of implant for fixation ectoprothesis in the temporal bone is approximately $95.7 \%$. The prosthetics can be modeled after the normal contralateral ear for appropriate symmetry, size, and projection. Therefore, craniofacial rehabilitation on cranial implants is a safe, reliable and predictable way to restore the patient's normal appearance [13, 14]. Peri-implant soft tissue reactions are most often associated with poor hygiene [15].

The issue of an integrated approach (otosurgeon with maxillofacial surgeon or plastic surgeon) to the rehabilitation of such patients is topical, considering the presence of a functional and aesthetic defect in congenital AEAC with microtia and a high probability of unsatisfactory functional, aesthetic outcomes and complications after reconstructive and plastic surgeries.

\section{Patients}

On the base of ear diseases department of Federal Scientific and Clinical Center of Otorhinolaryngology (FSCCO) of Federal Medico-Biological Agency of Russian Federation 47 patients aged from 7 to 61 years with congenital unilateral AEAC and microtia underwent surgery. Time of observation was from 2,3 month til 4,1 years.

All patients were divided into 3 groups due to indication and planned type of surgery (Table 1).

Table 1. Groups of patients.

\begin{tabular}{|c|c|c|c|}
\hline & $\begin{array}{c}\text { First group } \\
\text { (n=23 patients) }\end{array}$ & $\begin{array}{l}\text { Second group } \\
\text { ( } n=9 \text { patients) }\end{array}$ & $\begin{array}{c}\text { Third group } \\
\text { ( } n=15 \text { patients) }\end{array}$ \\
\hline Indications & $\begin{array}{l}\text { - Severe conductive } \\
\text { hearing loss of } 45-60 \mathrm{~dB} \text {. } \\
\text { - } 1^{\text {st }} \text { degree dysplasia. } \\
\text { - Auricular reconstruction is } \\
\text { not required }\end{array}$ & $\begin{array}{l}\text { - Severe conductive hearing } \\
\text { loss of } 45-60 \mathrm{~dB} \\
\text { - } 2^{\text {nd }} \text { and } 3^{\text {rd }} \text { degree dysplasia } \\
\text { - Children and young people } \\
\text { with no history of surgeries } \\
\text { before }\end{array}$ & $\begin{array}{l}\text { - Severe conductive hearing loss of } 45- \\
60 \mathrm{~dB} \text {. } \\
\text { - } 2^{\text {nd }} \text { and } 3^{\text {rd }} \text { degree dysplasia } \\
\text { - Adults and other patients who } \\
\text { underwent several surgeries before, } \\
\text { patients who have insufficient } \\
\text { development of local tissues, history of } \\
\text { auricular cancer, radiation, or trauma }\end{array}$ \\
\hline Type of surgery & $\begin{array}{l}\text { Reconstruction of the exter- } \\
\text { nal auditory canal and tym- } \\
\text { panoplasty with ossicular } \\
\text { chain reconstruction }\end{array}$ & $\begin{array}{l}\text { Reconstruction of the external } \\
\text { auditory canal, tympanoplasty } \\
\text { with ossiculoplasty and con- } \\
\text { comitant reconstruction of the } \\
\text { auricle by use of MEDPOR } \\
\text { and autologous tissues }\end{array}$ & $\begin{array}{l}\text { Reconstruction of the external auditory } \\
\text { canal, tympanoplasty with ossiculoplasty } \\
\text { and fixation of cranial osseointegrated } \\
\text { implants (COI). At the second stage indi- } \\
\text { vidual silicone prostheses were created }\end{array}$ \\
\hline
\end{tabular}

Patients were held standard preoperative general clinical examination, otoscopy, pure tonal audiometry and computer tomography (CT) of temporal bones. For the prediction results of surgical intervention, we used the R.A. Jahrsdoerfer scale in modification of Kh.M. Diab [16, 17]. The grading system of the assessment of anatomical features is presented in Table 1. It based on the analysis of preoperative CT imagies. For a score from 14 to 18 , the prognosis was assessed as excellent, from 11 to 13 - good, from 8 to 10 - satisfactory, with a score less than $8-$ no indications for surgical intervention.

Table 2. Grading scale in surgery to repair congenital aural atresia in modification of Kh.M. Diab.

\begin{tabular}{|l|l|c|}
\hline Anatomicalfeatures & & Point \\
\hline \multirow{4}{*}{ Size of antrum } & Decrease less than $30 \%$ & 2 \\
\cline { 2 - 3 } & Decrease by $30-50 \%$ & 1 \\
\cline { 2 - 3 } & Decrease more than $50 \%$ & 0 \\
\hline \multirow{4}{*}{ Location of sigmoid sinus } & Normal position & 2 \\
\cline { 2 - 3 } & Preposition less than $1 / 3$ of the mastoidal part & 1 \\
\cline { 2 - 3 } & Preposition covering 2/3 of the mastoidal part & 0 \\
\hline
\end{tabular}




\begin{tabular}{|c|c|c|}
\hline \multirow{3}{*}{$\begin{array}{l}\text { Location of the temporomandibular } \\
\text { joint }\end{array}$} & Mild dislocation & 2 \\
\hline & Moderate dislocation & 1 \\
\hline & Severe dislocation & 0 \\
\hline \multirow{3}{*}{ Pneumatization of the mastoid process } & Decrease less than $30 \%$ & 2 \\
\hline & Decrease $30-50 \%$ & 1 \\
\hline & Decrease more than $50 \%$ & 0 \\
\hline \multirow{3}{*}{ Middle ear cavity } & Wide & 2 \\
\hline & Middle & 1 \\
\hline & Absent & 0 \\
\hline \multirow{3}{*}{ Facial nerve } & $\begin{array}{l}\text { Normal position (blunt angle between tympanic part and mastoidal } \\
\text { parts of facial nerve) }\end{array}$ & 2 \\
\hline & Sharp angle formation & 1 \\
\hline & Abnormal position of facial nerve & 0 \\
\hline \multirow{2}{*}{ Maleus + incus } & Determined & 1 \\
\hline & Not determined & 0 \\
\hline \multirow{2}{*}{ Stapes } & Determined & 1 \\
\hline & Not determined & 0 \\
\hline \multirow{2}{*}{ Round window } & Determined & 1 \\
\hline & Not determined & 0 \\
\hline \multirow{2}{*}{ Ovale window } & Determined & 1 \\
\hline & Not determined & 0 \\
\hline \multirow{2}{*}{ Cortical layer in the implantation area } & More than $4,5 \mathrm{~mm}$ & 1 \\
\hline & Less than $4,5 \mathrm{~mm}$ & 0 \\
\hline
\end{tabular}

Distribution of points based on the CT evaluation of middle and inner ear structures. For a score from 14 to 18 the prognosis was assessed as excellent, from 11 to 13 - good, from 8 to 10 - satisfactory, with a score less than 8 - surgical intervention is not shown.

All surgeries were performed under general anesthesia with use of the system of monitoring of a facial nerve and the electromagnetic navigation system. The formation of the external auditory canal and tympanoplasty with ossiculoplasty was performed by the otosurgeon for all patients. Preparation of flaps, COI installation, fixation of Medporprostheses were performed together with the maxillofacial surgeon for patients from $2^{\text {nd }}-3^{\text {rd }}$ groups. For third group of patients 3D template for the future prosthesis was made by the medical engineer-mathematician at the preoperative stage (is used to mark up the operating field and the location of the implant).

\section{Atresia repair and tympanoplasty with ossicular chain reconstruction (all group of patients)}

A layered incision was made behind the rudimentary auricle, the cutaneous flap was removed, the cartilage that made up the rudiment external ear was removed (the cartilage was saved for later use during tympanoplasty). Performed anthromastoidotomy. Before the removal of the atretic plate, a posterior tympanotomy was completed, followed by its expansion in order to achieve a good visualization of the incustapedial joint. Then we disarticulate this joint to minimise the transmission of vibrations and prevent vibrotrauma of the inner ear and the development of sensoneural hearing loss in the postoperative period [7]. After disconnection of the incustapedial joint, the cutting burr removed the atretic plate and a single bone conglomerate of the malleus and the incus. The tympanic cavity was extended forward to the opening of the auditory tube, downand behind to the vertical portion (descending part) of the canal of the facial nerve. The external auditory canal was formed under the control of the navigation system by expanding the formed cavity up to the dura mater of the middle cranial fossa, anterior to the temporomandibular joint. Groove for the neotympanic membrane was formed in a receptive bone by a thin $2 \mathrm{~mm}$ 
diamond burr in order to fix neotympanic membrane and prevent its lateralization. After laying the fascial flap in the receiving place, ossiculoplasty with anadjustable partial titanium prosthesis with or without porous hydroxyapatite head was performed. In cases of using of partial titanium prosthesis without porous hydroxyapatite head the distal part of the prosthesis was separated from the fascial flap by a thinned autocartilage graft. Then a thin pedicled tongue-shaped flap was formed from the skin of the auricle's rudiments. It was laid on the front wall of the formed cavity (formed auditory canal). The other walls of the cavity were covered with free thin-layered skin grafts taken by the dermatome from the front surface of the hip. Fixation of the created neotympanic membrane and skin flaps was made by tamponade of the formed cavity with a hemostatic sponge and ear packing.

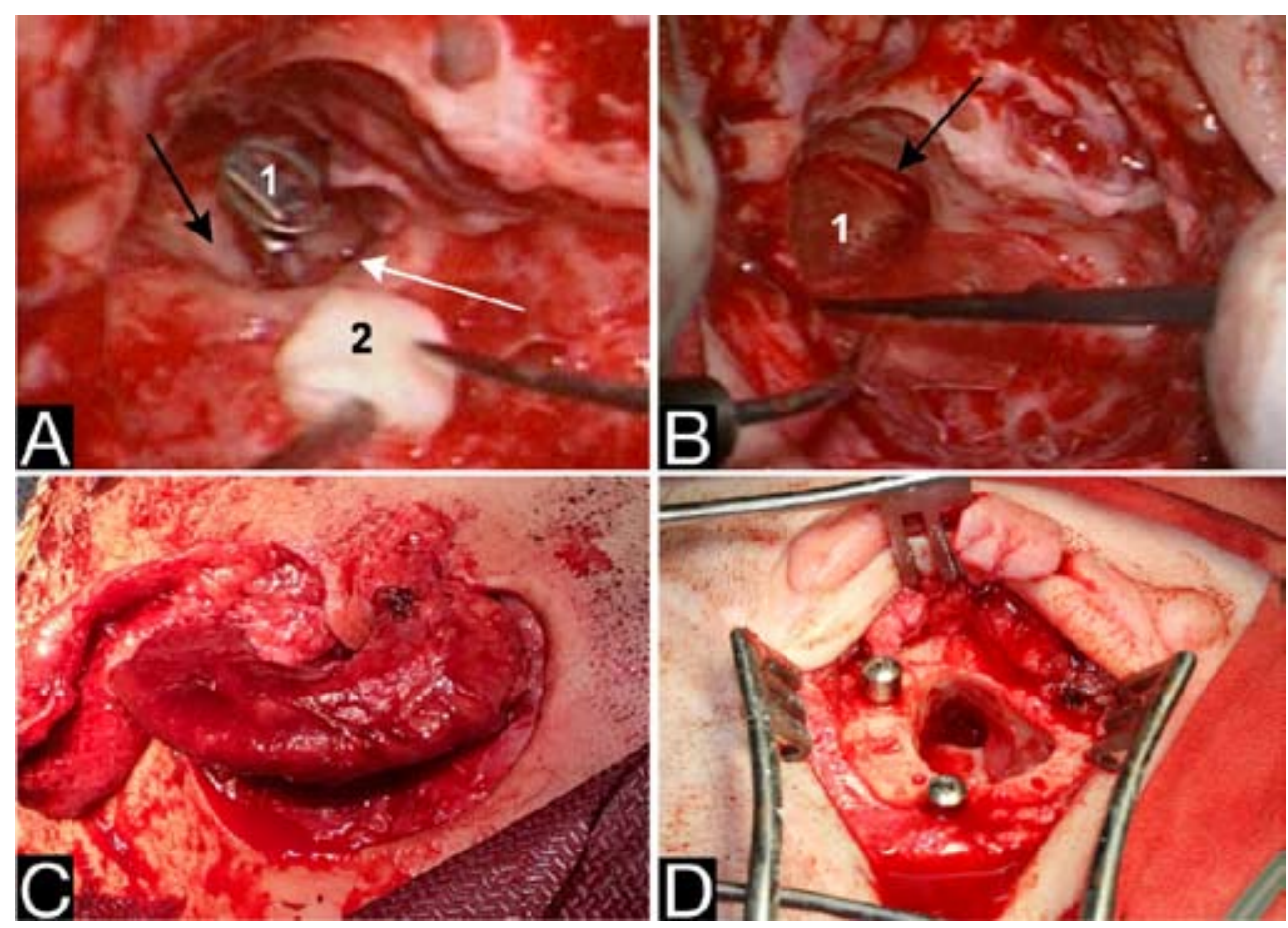

Figure 2. Intraoperative photo

\section{Legend:}

2a: Reconstruction of the tympanic cavity. 1 - a partial titanium ossicular prosthesis without hydroxiapatite head on stapes superstructures, 2 - an autocartilage graft which separates the prosthesis cap from the fascial flap. The black arrow indicates the tympanal segment of the facial nerve, the white arrow show the mastoid segment of the facial nerve. $2 \mathrm{~b}: 1$ - fascial flap. The black arrow indicates the created sulcus tympanicus.

2c: Medpor. Porous polyethylene implantation beneath a TPF flap.

$2 \mathrm{~d}$ :COI. Fixation of cranial osseointegrated implants.

\section{Porous polyethylene (Medpor) auricle reconstruction (second group of patients)}

The formation of the external auditory canal, middle ear structures and Medpor reconstruction were performed in one stage.

\section{Preparation}

The patient's ears were examined in regards to symmetry, size dimensions, rotation, projection, and position on the head relative to other facial structures. The normal ear was traced on to a clear radiographic film and used as a mirror guide to shape the Medpor construct. A measurement from the lateral canthus to the root of the helix (on the another side) was used to mark the take off of the helix of the reconstructed ear. The position of the auricle on the scalp was marked. In all cases we tried to preserve earlobe (the distal part of microtic ear) to achieve more natural results. The superficial temporal artery (STA) branches were traced on the scalp, using Doppler assistance, to prepare for the temporoparietal fascia (TPF) flap. A pedicled TPF flap based off the STA provided approximately 1 to $2 \mathrm{~mm}$ of soft tissue coverage, and was an important point contributing to low extrusion rates after Medpor reconstruction [18]. The polyethylene ear skeleton was comprised of two parts - ahelical rim 
and an ear base. Porous polyethylene material was molded into the desired ear shape and size based on a template tracing of the normal contralateral ear. Refinements were made to the Medpor intraoperatively using a scalpel per the discretion of the surgeon. The rim and base elements were then fused together using a high-temp cautery device.

\section{Surgical steps}

Once the incision was made down, the temporoparietal fascia was exposed. The TP flap was dissected on its anterior surface. To ensure adequate coverage over the entire Medpor framework without tension or tenting, the TPF flap should measure at least $11 \mathrm{~cm}$ in width and $11 \mathrm{~cm}$ in vertical height include both the anterior and posterior superficial branches of the STA [19]. The anterior border of the flap was separated from the deep temporal fascia caudal to the anterior branch of the STA. The flap also incised along the posterior, anterior and superior borders. The local skin was prepared properly to accept the Medpor implant and TP fascia for ear construction (anterior skin was elevated and converted to a thin full-thickness skin pedicle graft, wich was positioned on the anterior wall of the external audiotory canal). Cartilage was skeletonized from the local soft tissue and removed. Next, the fabricated Medpor construct was placed into the ideal position, the flap was draped over it. When it was possible we used earlobe to form the distal part of the ear. It's tissues were transposed posteriorly and fixed to Medpor. Two TLS drains were inserted: one underlied the Medpor construct 3-mm, the other the flap donor site 5-mm. The TP flap shrink-wrapped over the Medpor and achieved its contour. With an airleak, or ill-defined contour, reposition the TP flap until proper contour was achieved without a leak. The local skin of the microtic ear and mastoid mostly was only enough to cover the latero-posterior surfaces of the implant. A full-thickness skin graft was harvestedfrom the hip to provide added coverage for the reconstructed ear. Rapidly dissolving sutures were used to suture the skin grafts over the TPF Flap [20]. Air was expressed from beneath the graft and TPF flap. The reconstructed ear and incisions were covered with antibiotic ointment. Soft silicone putty was molded over the graft. Drains were usually injected with a long-acting anesthetic and connected to bulb suction to prevent seroma formation.

\section{Fixation of cranial osseointegrated implants (third group of patients)}

This step was performed only for third group of patients. In the area of implantsfixation (above the tip of the mastoid process and the temporal line) was made excision of subcutaneous fat and cut of the periosteum. In these area of the temporal bone percutaneous cranial titanium implants were installed with a depth of $4.5 \mathrm{~mm}$ with formers $5 \mathrm{~mm}$ high. The skin around the implants was stitched with the periosteumwith U-shaped seams. In the second stage (after 3-5 months) a soft individual silicone prosthesis of the auricle on magnetic fixation was made at the maxillofacial department (Figure 1c).

The wax model is corrected on the prosthetic placement. During the fitting a wax auricle the symmetry of the helix, lobule is taken into account, vertical and horizontal movements allow to place the wax model in the correct position. Correctly selected color and shade of silicone prosthesis, its adequate retention are the most important factors for improving the quality of life of patients. The method of internal multilayer staining of silicone prosthesis gives natural colors with medium transparency. The mixed silicone is packaged in a plaster mold, covered with an imprint, pressed and placed in a dry polymerizer. After polymerization the prosthesis is unpacked, if necessary pigmental streaks are applied by external application and varnishing in the polymerizer.

\section{Results and discussion}

All patients were under observation in our department during 2 weeks. On the second week we removed hemostatic sponges and ear packings, performed tamponade with new hemostatic sponges for prevention of restenosis. The second follow-up was after 1 month (during this visit we removed tampons, made aural toilet). For the assessment of anatomical and functional results we perfomed observation of patients every three months after surgeries at $1^{\text {st }}$ year, every six months at $2^{\text {nd }}$ and following years. The median postoperative follow-up was 3,2 years.

In anatomical results we took into account healing, epitelization and width of the EAC; position of a neotympanic membrane and prosthesis with auto cartilage graft; position of skin grafts and skin flaps; condition of Medpor endoprothesis or osseointegrated implants. 
Preoperative and postoperative audiograms (6 and 12 months, 2 years) were obtained and compared in all patients to evaluate functional results. Air conduction (AC) and bone conduction (BC) thresholds were recorded. Threshold frequencies of $0.5,1$, 2 , and $4 \mathrm{kHz}$ were used to calculate the pure-tone average. The differences between

the preoperative and the postoperative air-bone gap (ABG closure) were noted. A successful functional result was defined as a postoperative $A B G$ of 20 $-25 \mathrm{~dB}$.

Poor epidermization, bad-healing, restenosis of the EAC; ossicular chain prosthesis extrusion or displacement; sencorineural hearing loss; facial nerve dysfunction; necrosis of free skin flaps and fascia, infection and inflammation in the periimplant area; Medpor extrusion were classified as complications.
All groups of patients were performed functional reconstruction of the conductive pathway of sound from external ear to inner ear. Patients with excellent (24 patients) and good (23 patients) prognosis of operative interventionaccording to preoperative CT imagies of temporal bones were selected for the study. It was not necessary to transpose the facial nerve. After facial nerve's indentification and exposure in the mastoid segment it became possible to install an ossicular prosthesis on the superstructures of stapes, despite the atypical placement of the facial nerve canal and the absence of the vestibule and cochlea windows views [26, 27]. There were no symptoms of facial muscles paresis in the postoperative period. In all cases, we observed good healing of the postoperative cavity and its complete epidermisation. Stable anatomical results of the atresia repair were obtained using described technique (Fig. 3).
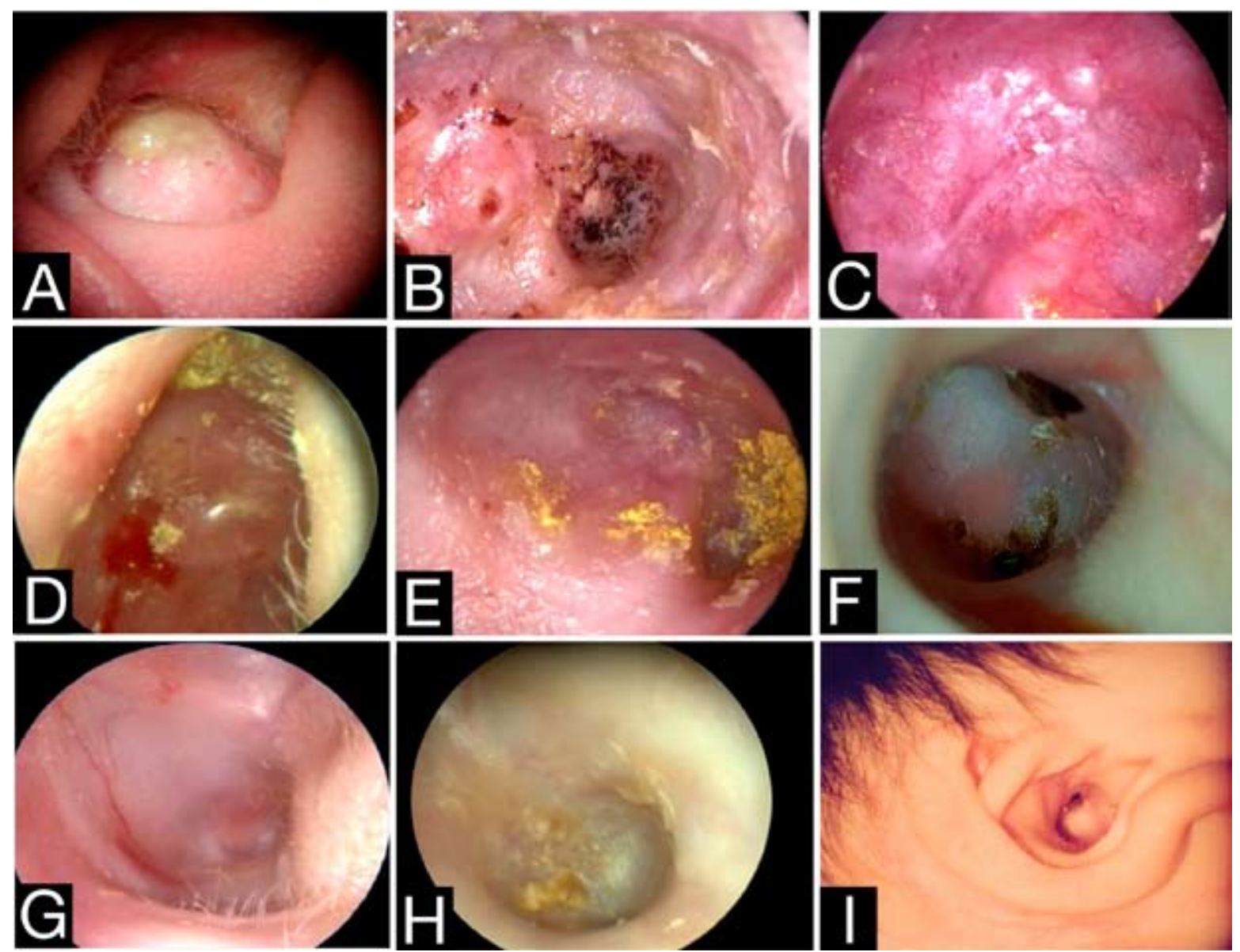

\section{Legend:}

3a: 2 months after surgery $3 b$ : 3 months after surgery 3c: 3 months after surgery $3 \mathrm{~d}$ : 6 months after surgery 3e: 8 months after surgery 3f: 12 months after surgery $3 g$ : 12 months after surgery $3 \mathrm{~h}: 1,8$ years after surgery 3i: 4 years after surgery

Figure 3. Anatomical results after tympanoplasty and ossiculoplasty in case of congenital atresia of external auditory canal. 
There were no cases of restenosis of the postoperative external auditory canal, but we faced to (moderate) lateralization of the neotympanic membrane with a blunting of the anterior angle in two patients. According to pure tonal audiometry thresholds of $\mathrm{AC}$ were in the range of $25-35 \mathrm{~dB}$ with an $\mathrm{ABG}$ of 21-23,5 dB. Functional results are shown in Diagram 1.

Diagram 1. Functional results after congenital atresia repair
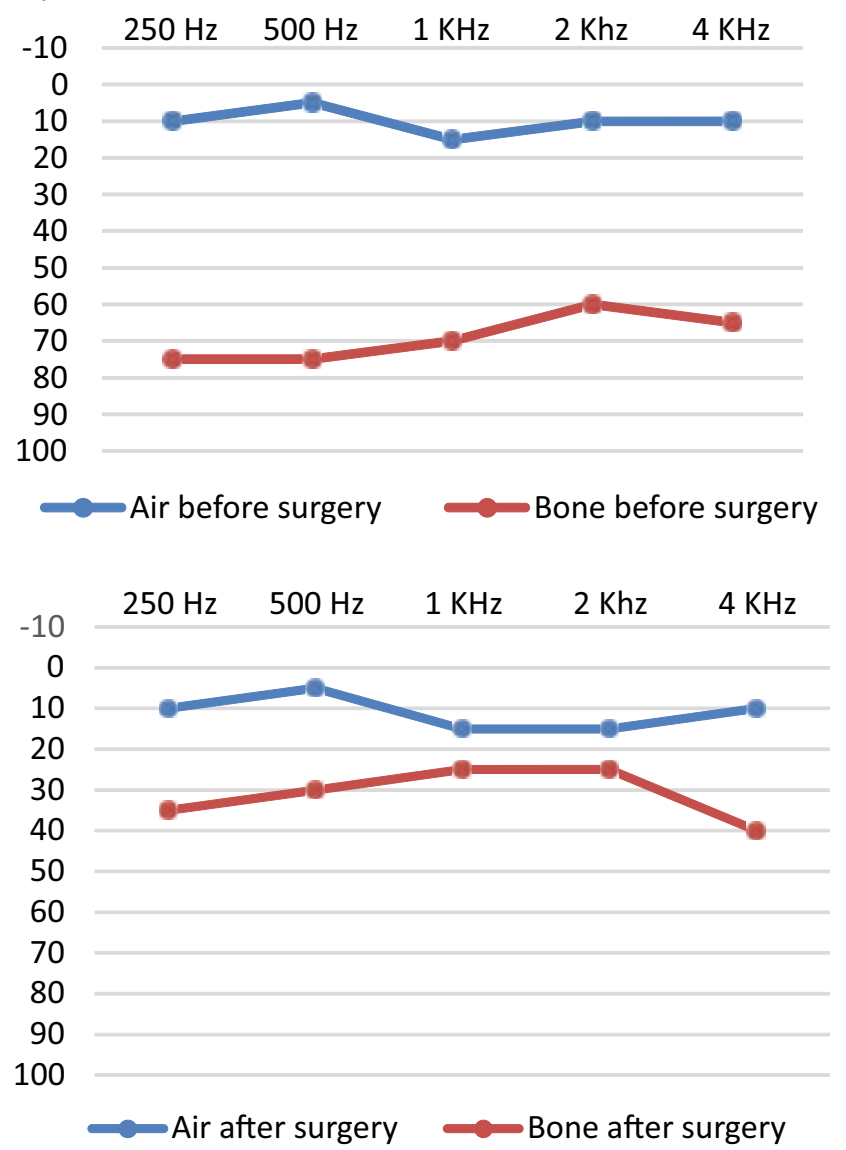

The air-bone gap in the preoperative period was average $44.6 \mathrm{~dB} \pm 3,2 \mathrm{~dB}$ before surgery and significantly decreased to $17,0 \pm 3.2 \mathrm{~dB}$ at 8 months -1 year postoperatively $(n=47)$. It should be regarded as a good functional outcome.

In case of auricle reconstruction the successful interaction between the otosurgeon and the maxillofacial surgeon made it possible to provide creation of a broad auditory canal and enough preservation of the cortical layer of the temporal bone for installation of the cranial osseointegrated implants (COI) or Medpor. The aesthetic result was additionally evaluated in the second and third patient groups to anatomical and audiological results. Medpor is a highly durable, biocompatible, nonresorbable, and minimally reactive material, which is used in craniofacial reconstructive surgeries with favorable long-term stability. One of the biggest disadvantages of this method is high cost of porus prosthetic implats. Treatment for most patients, who were provided Medpor reconstruction in FSCCO, was funded from budget of the Russian Federation. In our practice there were 2 cases of limited extrusion and dry necrosis of free skin flaps and fascia in the area of implant. Complications were successfully managed with partial incision, small turnover flap and local skin flap cover. These patients were on a prolonged postoperative antibiotic course and observation. We have no experience of Medpor implant explantations.
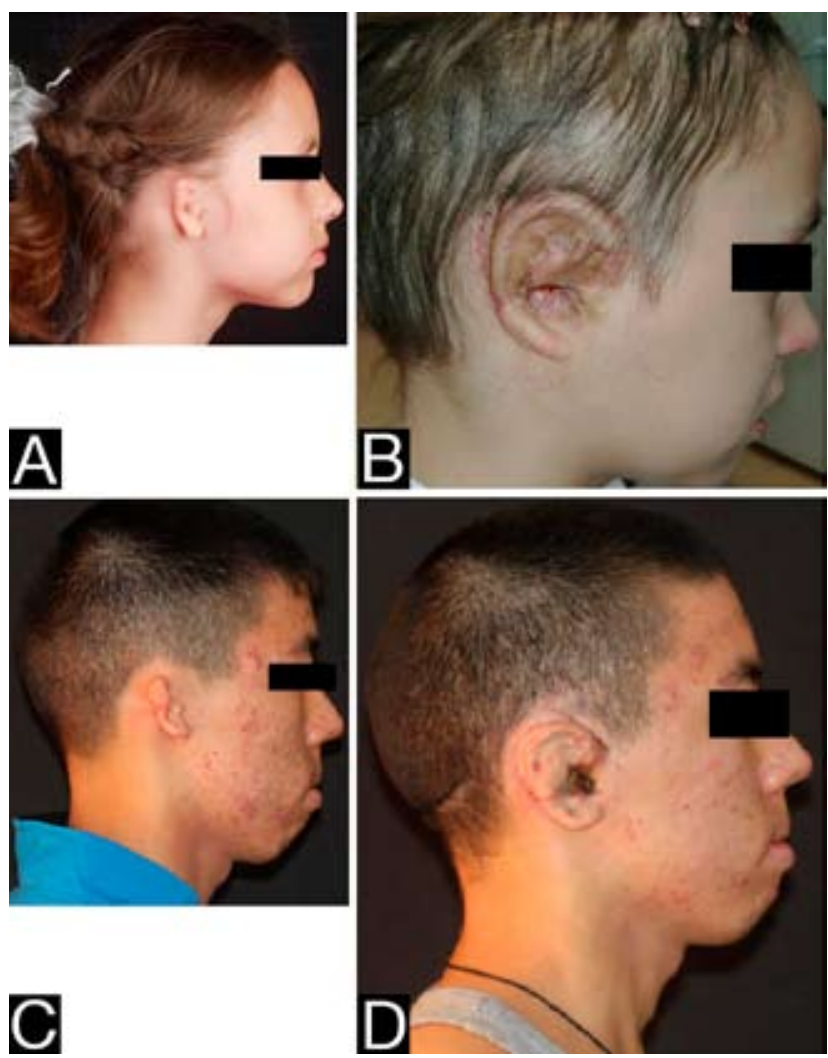

$4 a$ - before the surgery

$4 \mathrm{~b}$ - after Medpor reconstruction of auricle

$4 \mathrm{c}$ - before the surgery

$4 d$ - after Medpor reconstruction of auricle

Figure 4. Anatomical results after Medpor implantation.

Ectoprosthetics with fixation on cranial implants offers an excellent reconstructive option that provides perfect symmetry, color and anatomical details. The individual auricle prosthesis completely covered up a congenital defect (Figure 5). 

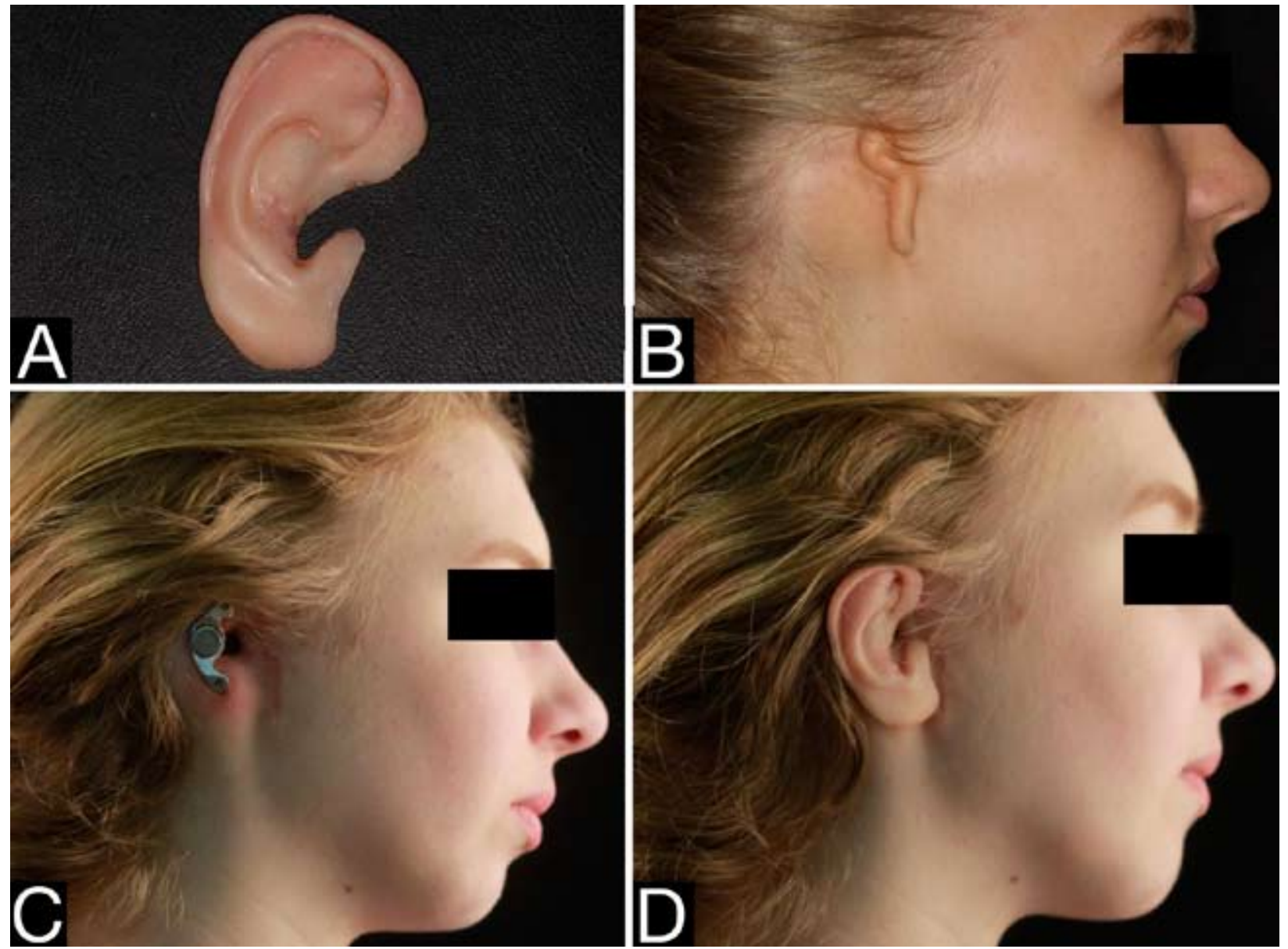

$5 a-$ Appearance of the silicone prosthesis of the auricle on magnetic fixation, the external surface

$5 b$ - cranial implants with magnetic fixation for the auricle prosthesis

$5 c$ - Appearance of the patient before the surgery

$5 d$ - after the installation of an auricle prosthesis

Figure 5. Aesthetic results after cranial osseointegrated implants.

Osseointegrated implants provide a reliable fixation of the ectoprosthesis, which eliminates using of glues, double-sided adhesive tape or other fixation methods that can compromise the stability of the prosthesis. The use of ectoprostheses improves the appearance of the patient. The good quality of the prosthesis fixation and its simplicity of use ensures a high level of patient activity improving the patient's quality of life. However, infection and inflammation can lead to loss of the implant. Inflammation around cranial implants was observed in 1 patient with squamous cell carcinoma in history. This complication was provoked by scarred poorly perfused mastoid skin after previous surgery, chemotherapy and radiation in anamnesis. It was managed with local treatment and meticulous postoperative care for a long time. Our experience led us to the conclusion, that condition of peri-implant soft tissues is one of the most important factors for achieving a good long-term result of treatment. The creation of a thin subcutaneous layer in the near implant area during surgery and excellent hygiene in the postoperative period allows to reduce the frequency of inflammatory reactions from surrounding soft tissue [28].

\section{Conclusion}

The application of the method of lining formed bone walls of the external auditory canal with a skin pedicled flap and free skin grafts makes it possible to achieve stable anatomical result. Ossiculoplasty with titanium prostheses and tympanoplasty with auto-fascia provide a significant hearing improvement in patients with congenital atresia of the external auditory canal.

Simultaneous surgeries with atresia repair; tympanoplasty and Medpor implantation or setting of 
ectoprosthetic on COI can be successfully used to improve hearing, replace abnormal ear in different categories of patients according to indications and return them to the normal life. Medpor reconsctruction is more complicated and expensive surgery demanding on long time of general anesthesia.It is the best choice for children and young people with no history of prior microtia plasties or another surgeries in this area before.

The main advantages of ectoprosthetics in comparison with traditional surgical methods of reconstruction are: a) simplicity of surgical technique;

b) the predictable outcome;

c) high speed of rehabilitation. Ectoprosthetics are useful for patients with history of cancer, trauma, radiation, for those who underwent surgeries before and have insufficient development of local tissues.

Disclosure of interest. The authors declare that they have no conflicts of interest concerning this article.

\section{References}

1. Swartz J, Faerber E. Congenital malformations of the external and middle ear: high-resolution CT findings of surgical import. American journal of roentgenology.-1985; 144 (3): 501-506. Doi: 10.2214/ajr.144.3.501

2. Ishimoto S., Ito K, Yamasoba T., Kondo K., Karino S., Takegoshi H., Kaga K. Correlation between microtia and temporal bone malformation evaluated using grading system. Archives of otolaryngology - head \& neck surgery. 2005; 131 (4): 326-329. Doi: 10.1001/archotol.131.4.32

3. Siegert R., Weerda H., Remmert S. Embryology and surgical anatomy of the auricle. Facial Plast Surg.

4. 1994; 10(3): 232-43. Doi: 10.1055/s-2008-1064574

5. Nazaryan D.N., Khazaryan A.E., Karayan A.S., Chausheva S.I., Yarantzev S.V. Anaplastology as the part of plastic and maxillo-facial surgery. Head\&Neck (rus.edition). Journal for treatment specialists in head\&neck pathology. 2014; 4: 28-34. (In Russ)

6. Diab H.M. Surgical technique in cases with congenital atresia of the meatus acusticus external. RossiyskayaOtorinolaringologiya. 2011; 5 (54): 41-46.(In Russ)

7. Kriukov A.I., Kariakina I.A., Mileshina N.A. Canaloplasty in the rehabilitation of patients presenting with microtia. Vestnik otorinolaringolo gii.2011;4: 49-52. (In Russ)

8. Diab H.M., Anikin I.A., Eremin S.A. Surgical technique in cases with congenital atresia of the meatus acusticus external to prevent sensoneural hearing loss. RossiyskayaOtorinolaringologiya. 2011; 6 (55): 36-39.(In Russ)

9. Zhao S., Han D., Wang Z., Li J., Qian Y., Ren Y., Dong J. An imaging study of the facial nerve canal in congenital aural atresia. Ear Nose Throat J. 2015; 94 (10-11): E6-13.

10. Qin F., Zhang T., Dai P., Yang L. Anatomic Variants on Computed Tomography in Congenital Aural Atresia and Stenosis. Clinical and Experimental Otorhinolaryngology. 2015; 8 (4): 320-328. Doihttps://doi.org/10.3342/ceo.2015.8.4.320

11. Diab H.M. Classification of the ear malformations.RossiyskayaOtorinolaringologiya. 2012; 2(57): 154-161.(In Russ)

12. Ali K, Trost JG, Truong TA, Harshbarger RJ. Total Ear Reconstruction Using Porous Polyethylene. 3rd. SeminPlast Surg. 2017 Aug;31(3):161172. doi: 10.1055/s-0037-1604261. Epub 2017 Aug 9. Review.

13. Kharazyan A.E., Nazaryan D.N., Chausheva S.I., Yarantsev S.V., Chernenkiy M.M., Kialov G.G. Complex rehabilitation of patients with combined defects of midface using cranial implants with immediate loading. Plastic surgery and cosmetology. 2015; 3: 260-267.(In Russ)

14. Mileshina N.A., Osipenkov S.S., Bakhshinyan V.V., Tavartkiladze G.A. The novel possibilities for the rehabilitation of the patients presenting with congenital external and middle ear malformations. Vestnikotorinolaringologii. 2014;(2): 33-36. (In Russ)

15. Curi M., Oliveira M., Molina G., Cardoso C., Oliveira Lde G., Branemark P., RibeiroKde C. Extraoralimplants in the rehabilitation of craniofacial defects: implant and prosthesis survival rates and peri-implant soft tissue evaluation. Journal of Oral \& Maxillofacial Surgery. 2012; 70 (7):1551-7. doi:10.1016/j.joms.2012.03.011

16. Holgers K.M., Tjellstrцm A., Bjursten L.M., Erlandsson B.E. Soft tissue reactions around percutaneous implants: a clinical study of soft tissue conditions around skin-penetrating titanium implants for bone-anchored hearing aids. The American journal of otology. 1988; 9(1): 56-9.

17. Jahrsdoerfer R., Yeakley J., Aguilar E., Cole R., Gray L. Grading system for the selection of patients with congenital aural atresia. Otology \& Neurotology.1992; 13(1): 6-12. doi:10.1097/00129492-199201000-00004

18. DiabKh. M.Surgical treatment of external, middle, internal ear malformations. The topic for doctor's degree. Sain-Petersburg; 2012. Доступнопо http://lornii.ru/resources/autoref/diab hm.pdf. (In Russ)

19. Berghaus A, Stelter K, Naumann A, Hempel JM. Ear reconstructionwith porous polyethylene implants. AdvOtorhinolaryngol 2010; 68:5364

20. Romo T III, Reitzen SD. Aesthetic microtia reconstruction withMedpor. Facial Plast Surg. 2008;24(01):120-128.

21. Reinisch JF, Lewin S. Ear reconstruction using a porous polyethylene framework and temporoparietal fascia flap. Facial Plast Surg. 2009;25(03):181-189.

22. Memari F., Mirsalehi M., Jalali A. Congenital aural atresia surgery: transmastoid approach, complications and outcomes. Eur Arch Otorhinolaryngol. 2012; 269(5): 1437-44. doi: 10.1007/s00405-011-1785-6

23. McKinnon B.J., Jahrsdoerfer R.A. Congenital auricular atresia: update on options for intervention and timing of repair. Otolaryngologic Clinics of North America. 2002; 35(4): 877-890. doi:10.1016/s0030-6665(02)00058-0

24. Molony T.B., de la Cruz A. Surgical Approaches to Congenital Atresia of the External Auditory Canal. Otolaryngology -- Head and Neck Surgery. 1990; 103(6): 991-1001. doi:10.1177/019459989010300618 
25. Teufert K. Advances in congenital aural atresia surgery: Effects on outcome. Otolaryngology - Head and Neck Surgery.2004; 131(3): 263-270. doi:10.1016/j.otohns.2004.03.006.

26. Edfeldt L., Strцmbдck K. Surgical treatment of congenital aural atresia - is it still justified? ActaOto-Laryngologica. 2015; 135(3): 226-32.doi: 10.3109/00016489.2014.979437.

27. Jahrsdoerfer R. The Facial Nerve in Congenital Aural Atresia.Otology\&Neurotology.2002; 23(1): 64-65.doi:10.1097/00129492-20020000100166.

28. DiabKh., Daikhes N., Kondratchikov D.; Pashchinina O., Ospanova M. A retrofacial access for cochlear implantation in bilateralcongenital atresia of the external auditory canal.Vrach (The Doctor).2015; 10: 71-74

29. Goiato M.C., Takamiya A.S., Alves L.M., dos Santos D.M. Postsurgical care for rehabilitation with implantretainedextraoral prostheses. Journal of Craniofacial Surgery.2010; 21(2): 565-567.doi:10.1097/scs.0b013e3181d02

\section{Corresponding Author:}

\section{Kh. Diab}

Federal Research Clinical Center of Otorhinolaryngology of Federal Medical Biological Agency of Russia,

(Director-Professor N. A. Daikhes),

123182, Moscow, Russia

E-mail: hasandiab@mail.ru

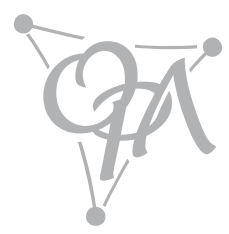

